\title{
Health Technology Assessment of Belimumab: A New Monoclonal Antibody for the Treatment of Systemic Lupus Erythematosus
}

\author{
Maria Lucia Specchia, ${ }^{1}$ Chiara de Waure, ${ }^{1}$ Maria Rosaria Gualano, ${ }^{2}$ Andrea Doria, ${ }^{3}$ \\ Giuseppe Turchetti, ${ }^{4}$ Lara Pippo, ${ }^{5}$ Francesco Di Nardo, ${ }^{1}$ Silvio Capizzi, ${ }^{1}$ Chiara Cadeddu, \\ Flavia Kheiraoui, ${ }^{1}$ Luca Iaccarino, ${ }^{3}$ Francesca Pierotti, ${ }^{4}$ Ilaria Palla, ${ }^{4}$ Maria Assunta \\ Veneziano, ${ }^{1}$ Daniela Gliubizzi, ${ }^{1}$ Antonella Sferrazza, ${ }^{1}$ Nicola Nicolotti, ${ }^{1}$ Rolando Porcasi, ${ }^{5}$ \\ Giuseppe La Torre, ${ }^{6}$ Maria Luisa Di Pietro, ${ }^{1}$ and Walter Ricciardi ${ }^{1}$ \\ ${ }^{1}$ Institute of Public Health, Catholic University of the Sacred Heart, 00168 Rome, Italy \\ ${ }^{2}$ Department of Public Health, University of Turin, 10126 Turin, Italy \\ ${ }^{3}$ Rheumatology Department, Padua Hospital, 35128 Padua, Italy \\ ${ }^{4}$ Institute of Management, Scuola Superiore Sant’Anna, 56127 Pisa, Italy \\ ${ }^{5}$ GSK, 37135 Verona, Italy \\ ${ }^{6}$ Department of Public Health and Infectious Diseases, Sapienza University of Rome, 00185 Rome, Italy
}

Correspondence should be addressed to Chiara de Waure; chiara.dewaure@rm.unicatt.it

Received 2 May 2014; Accepted 29 June 2014; Published 17 August 2014

Academic Editor: Norberto Ortego-Centeno

Copyright ( 2014 Maria Lucia Specchia et al. This is an open access article distributed under the Creative Commons Attribution License, which permits unrestricted use, distribution, and reproduction in any medium, provided the original work is properly cited.

\begin{abstract}
Objective. Systemic lupus erythematosus (SLE) is treated with anti-inflammatory and immunosuppressive drugs and off-label biologics. Belimumab is the first biologic approved after 50 years as an add-on therapy for active disease. This paper summarizes a health technology assessment performed in Italy. Methods. SLE epidemiology and burden were assessed using the best published international and national evidences and efficacy and safety of belimumab were synthesized using clinical data. A cost-effectiveness analysis was performed by a lifetime microsimulation model comparing belimumab to standard of care (SoC). Organizational and ethical implications were discussed. Results. Literature review showed that SLE affects 47 per 100,000 people for a total of 28,500 patients in Italy, 50\% of whom are affected by active form of the disease despite SoC. These patients, if autoantibodies and anti-dsDNA positive with low complement, are eligible for belimumab. SLE determines work disability and a 2-5-fold increase in mortality. Belimumab with SoC may prevent 4,742 flares in three years being cost-effective with an incremental costeffectiveness ratio of $€ 32,859$ per quality adjusted life year gained. From the organizational perspective, the development of clear and comprehensive clinical pathways is crucial. Conclusions. The assessment supports the use of belimumab into the SLE treatment paradigm in Italy.
\end{abstract}

\section{Introduction}

Systemic lupus erythematosus (SLE) is a chronic inflammatory autoimmune disease harming skin, joints, kidneys, lungs, nervous system, and serous membranes which mostly occurs in fertile women [1]. The feature that affects patient's long term survival is tissue damage, especially when organs such as kidneys are involved [2-4].

Recent EULAR (EUropean League Against Rheumatism) recommendations for the management of patients affected by SLE were published in 2008 [5]. In 2010, EULAR recommendations for neuropsychiatric lupus were also defined 
[6] while, in 2012, the American College of Rheumatology (ACR) released recommendations for the management of lupus nephritis [7].

In the last 50 years no new drugs for SLE have been approved. Therapy for SLE includes nonsteroidal antiinflammatory drugs (NSAIDs), corticosteroids, antimalarial agents, and immunosuppressant drugs [8]. None of these treatments has a specific target; rather, their aim is the reduction of inflammation and unspecific suppression of the immune system. In the last 15 years immunosuppressant and immunomodulating drugs, which act on specific target immune cells, were added as second-line treatment. Despite the large availability of these treatments, approximately $50 \%$ of patients have persistence of active SLE or the occurrence of a relapse $[9,10]$ which both require modifications of therapy, most commonly with an increase of corticosteroid dosage and introduction of immunosuppressant drugs [8].

This paper summarizes the results of a health technology assessment (HTA) of belimumab, which was approved at the dosage of $10 \mathrm{mg} / \mathrm{kg}$ by the US Food and Drug Administration (FDA) on March 2011 and by the European Medicines Agency (EMA) on July 2011.

Belimumab is indicated as an add-on treatment for SLE in adults with a positive autoantibody test whose disease is still highly active (e.g., anti-dsDNA positive and low complement) despite standard treatment with the exception of patients with severe active lupus nephritis or severe active central nervous system lupus [11]. Because of the unmet therapeutic need of these patients, belimumab could be a much awaited treatment from both physicians and patients and may potentially change the therapeutic framework of SLE in Italy.

The HTA of belimumab aims to fill the need for knowledge about this treatment and to establish a good basis for its proper use. Moreover the HTA may direct the design of further research and the information or training of health professionals and/or patients. The final purpose is thus to contribute to a greater effectiveness and efficiency of the decision making process.

\section{Methods}

An HTA was performed to evaluate the value of using belimumab for treating patients affected by SLE in the Italian context.

2.1. Epidemiology of the Disease. Target condition and population were defined using systematic reviews of the literature. Studies published on PubMed dealing with prevalence and incidence of SLE worldwide and in Italy were examined to define the frequency of the disease. The same approach was used to address the frequency of people with disability due to SLE. In order to perform these reviews the following keywords were used: "Lupus Erythematosus, Systemic" [Mesh], LES, "Epidemiology" [Mesh], incidence, prevalence, burden, and frequency.

2.2. Efficacy and Safety of Belimumab. A literature search was performed in PubMed and Embase to identify randomized
TABLE 1: Model features.

\begin{tabular}{ll}
\hline Patients & 50,000 \\
\hline $\begin{array}{l}\text { Maximum treatment period } \\
\text { with belimumab }\end{array}$ & 10 years \\
\hline $\begin{array}{l}\text { Maximum effect related to } \\
\text { belimumab }\end{array}$ & Lifetime \\
\hline Subgroup & $\begin{array}{l}\text { Patient with low complement and } \\
\text { anti-dsDNA }\end{array}$ \\
\hline Responder rule & $\begin{array}{l}\text { Reduction SELENA-SLEDAI } \geq 4 \\
\text { at 24th week }\end{array}$ \\
\hline Natural history model & $\begin{array}{l}\text { JH-AMS* forced in, involvement } \\
\text { removed }\end{array}$ \\
\hline $\begin{array}{l}\text { Long term disease activity } \\
\text { model }\end{array}$ & $\begin{array}{l}\text { Adjusted natural history models } \\
\text { (NHM) }\end{array}$ \\
\hline $\begin{array}{l}\text { One-year steroid model } \\
\text { * Johns Hopkins University (JH) Adjusted Mean SLEDAI (AMS). }\end{array}$
\end{tabular}

clinical trials (RCTs) reporting the efficacy and safety of belimumab. In order to perform these reviews the following keywords were used: Belimumab, Efficacy, Safety, "Clinical Trial." Moreover European Public Assessment Report (EPAR) and data supplied by marketing authorization holder (GlaxoSmithKline) were reported.

2.3. Cost-Effectiveness Analysis. A cost-effectiveness analysis was performed from both the Italian National Health Service (NHS) and societal perspectives. In particular, a microsimulation cost-effectiveness model was developed to assess the cost-effectiveness of belimumab $(10 \mathrm{mg} / \mathrm{kg})+$ the standard of care (SoC) compared to the $\mathrm{SoC}$ alone. The model was developed by Pharmerit International Company on Excel software and then adapted to the Italian context. Table 1 shows the main features of the economic model.

The long term outcomes used in the model were based on data from the BLISS trials [12] and the Johns Hopkins observational cohort study [13]. The BLISS trials informed the likelihood of response at week 24, the change in SELENASLEDAI (Systemic Lupus Erythematosus Disease Activity Index) score up to week 52, the likelihood of discontinuation, and the effect of SELENA-SLEDAI score on utility and treatment costs. The efficacy recorded in the trials was projected over the 10-year maximum treatment period, in accordance with NICE report [14]. The main parameters used in the base case scenario are shown in Table 5.

Cost data $(€, 2011)$ were collected from the National Tariffs [15] and, when not available, through the international literature adjusting for currency and inflation [16-19].

As the analysis was conducted from both societal and NHS perspectives, direct and indirect costs were considered $[20,21]$. In particular, direct costs were related to diagnostic tests, specialist visits, and organ damage. Regarding indirect costs, the human capital approach was followed to carry out the analysis.

Utility data, used to calculate quality adjusted life years (QALYs) related to the different health states (Figure 1), were retrieved from international literature, on the basis of the 


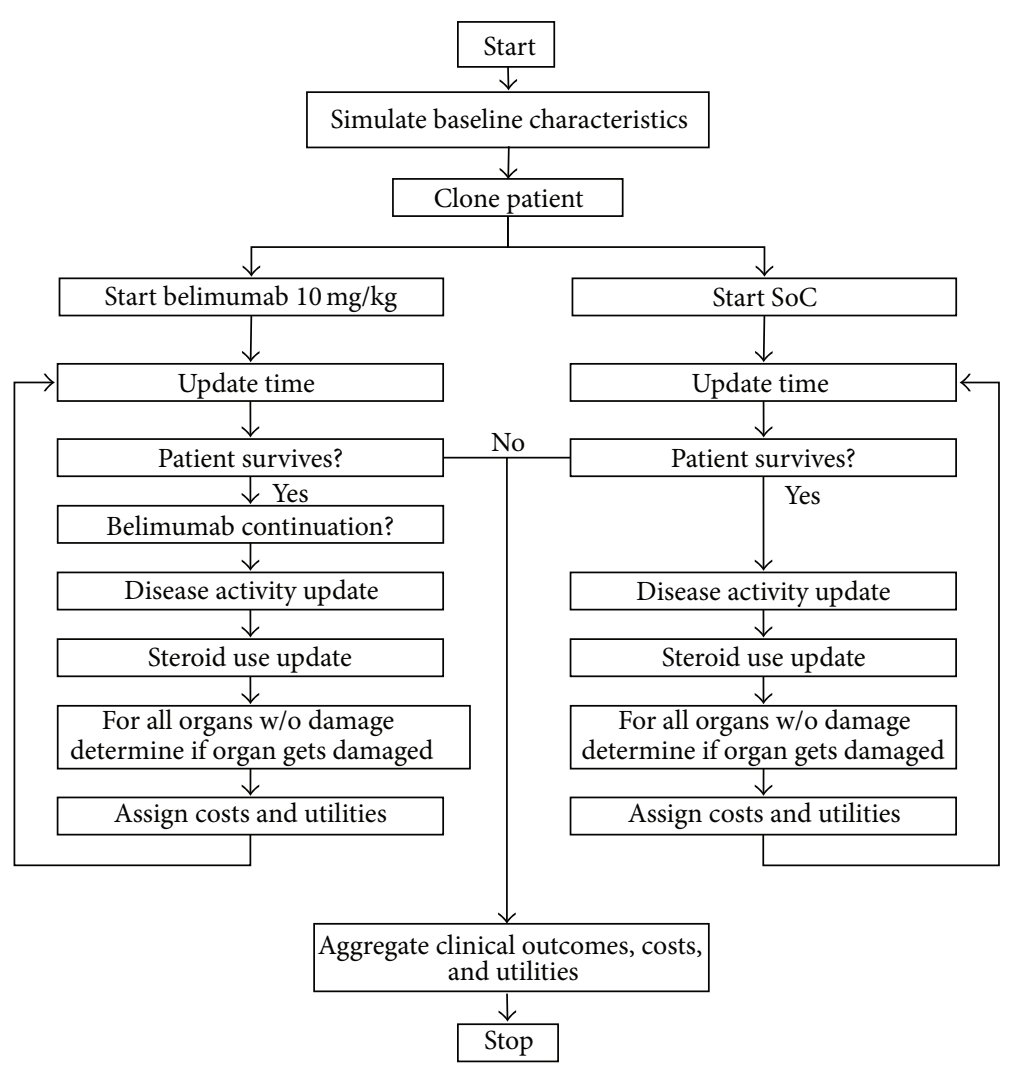

FIgURE 1: Pathways followed by patients entering the two different treatments.

utilities elicited within the BLISS trial that considered a representative sample of UK patients [14].

The horizon of the analysis was lifetime and costs and benefits were discounted at 3\% yearly. Results were reported as incremental cost-effectiveness ratio (ICER), expressed in terms of incremental cost per life year (LY) gained and QALY gained.

To assess the robustness of the base case results, univariate and probabilistic sensitivity analyses (PSA) were conducted on the following critical parameters (the distribution is reported in brackets):

(i) change in SELENA-SLEDAI score at week 52 (multivariate normal distribution);

(ii) change in SELENA-SLEDAI score according to the natural history model (multivariate normal distribution);

(iii) discontinuation rate (normal distribution);

(iv) probability of response (gamma distribution);

(v) mortality and organ damage development probabilities according to the natural history model (multivariate normal distribution);

(vi) standardized mortality rates (normal distribution);

(vii) utility values (multivariate normal distribution);

(viii) organ damage disutility (gamma distribution);

(ix) costs associated with each SELENA-SLEDAI score (gamma distribution); (x) organ damage costs (gamma distribution);

(xi) indirect costs (normal distribution).

A cost-effectiveness acceptability curve (CEAC) was reported to assess how the probability of cost-effectiveness of belimumab varies according to different threshold values.

2.4. Organizational Aspects and Impacts. A literature review was performed to analyze health needs, healthcare priorities, and quality of life (QoL) of patients with SLE. These aspects were identified as a result of a discussion with key opinion leaders involved in SLE management. The keywords used to perform the review were "Lupus Erythematosus, Systemic" [Mesh], LES, health needs, healthcare priorities, and quality of life.

2.5. Ethical Evaluation. The ethical issues linked to the utilization of the product were taken into account through a framework including epistemological data, anthropologic reference, and ethical evaluation. With respect to human values, the following elements were considered: risk/benefit ratio, QoL, patient's autonomy, and social justice.

\section{Results}

3.1. Epidemiology of the Disease. SLE is due to both genetic and environmental factors which leads to a deregulation of the immune response. The diagnosis relies on clinical 
anamnesis, medical investigation, and laboratory tests which are useful to exclude different diseases. Eleven criteria were developed and provided by the ACR to make diagnosis [22] and have been recently revised and validated by the Systemic Lupus International Collaborating Clinics (SLICC) group [23]. The diagnosis is often late because of the insidious onset [24]. The disease has a remitting-relapsing pattern with the occurrence of flares, with objective increase in disease activity marked by onset or worsening of signs and symptoms $[2,3,25]$. The SLEDAI, the British Isles Lupus Assessment Group (BILAG), the Physician's Global Assessment (PGA), and the SLE Responder Index (SRI) were developed to assess disease activity.

The disease determines joint pain, which occurs in about $90 \%$ of patients $[1,26,27]$; skin rashes, which develop during the course of the disease in $85 \%$ of patients [1, 24, 26-28]; glomerulonephritis, in about $50 \%$ of patients, which may cause renal failure in $20 \%$ [28-30].

The disease is more common in non-Caucasian people, in particular Black and Hispanic [31, 32]. It affects women in $80-90 \%$ of cases with a female/male ratio ranging between 6 and $10[31,32]$. The peak of incidence is reached between 15 and 44 years of age $[31,32]$.

The systematic review of the literature yielded 29 studies performed in Europe or America from 1980 on. Twenty-one studies were carried out in Europe on people belonging to Caucasian race mainly. The prevalence varied from 20 to 50 cases per 100,000 while the incidence ranged from 2 to 5 cases per 100,000 each year.

In Italy only two small studies addressed the epidemiology of SLE [33, 34]: prevalence ranged between 57.9 and 71 cases per 100,000 while incidence varied from 1.15 to 2.6 per 100,000 . To calculate the population eligible to receive belimumab, data were searched in the literature, specifically, the percentage of patients with active disease and low complement levels. Chronic active disease was defined according to a SLEDAI-2K $\geq 2$ (excluding the serology) in at least two out of three annual medical examinations, whereas the relapsing-remitting disease was defined as a SLEDAI-2K $\geq 2$ in at least one out of three annual medical examinations. Two studies released estimates of patients responding to these criteria $[9,10]$ for a mean value of $50 \%$. A direct estimate of the presence of low complement together with anti-ds DNA positivity was provided by the Systemic Lupus Erythematosus Cost of Care In Europe Study (LUCIE) [35] which yielded a value of $39.6 \%$. Considering a mean prevalence of $0.047 \%$ [36] the population of patients affected by SLE in Italy would be approximately 28,500 , whereas the population eligible to receive belimumab would be approximately 5,300.

The survival of SLE patients has improved throughout the years and it is now over $90 \%$ at 5 and 10 years $[37,38]$. Daily life activities most influenced by the disease include vigorous physical activities in $83.9 \%$ of cases, housework in $79.4 \%$, sleep in $72.9 \%$, work activities in $70.7 \%$, and household business in $67.8 \%$ [39]. About one-third of patients became unable to work and are obliged to retire after 3-12 years following the diagnosis.
3.2. Efficacy and Safety of Belimumab. The search identified one phase I study (LBSL01) [40], one randomized, double blinded phase II study controlled with placebo (LBSL02) [41], two randomized, double blinded phase III studies controlled with placebo (C1056 or BLISS-76 and C1057 or BLISS-52) $[42,43]$, and a combined analysis of phase III clinical trials [12].

Main results of the phase II and III trials on belimumab are reported in Table 2 . In the BLISS-76 and BLISS-52 phase III pivotal trials, the study population was treated with belimumab and SoC (corticosteroids, antimalarial agents, NSAIDs, cytotoxic chemotherapy, and immunosuppressive or immunomodulatory drugs) while controls received SoC plus placebo. Primary endpoint was a reduction in the SRI at week 52 in both studies. Secondary endpoints were flares frequency, time between flares (BLISS-76 study only), and effect of the treatment on corticosteroids dosage. All endpoints underwent an intention-to-treat analysis. Two belimumab doses were studied $(1 \mathrm{mg} / \mathrm{kg}$ and $10 \mathrm{mg} / \mathrm{kg})$. In both phase III trials, the primary endpoint was achieved in a significantly greater proportion of patients treated with the $10 \mathrm{mg} / \mathrm{kg}$ dosage compared to patients treated with placebo ( $P=0.0006$ in BLISS-52 and $P=0.02$ in BLISS-76). On the contrary, no statistically significant differences were observed between $1 \mathrm{mg} / \mathrm{kg}$ belimumab and placebo groups in the BLISS-76 study. A greater response to $10 \mathrm{mg} / \mathrm{kg}$ belimumab was also observed in the subgroup with more active disease (placebo: $31.7 \%$; belimumab $1 \mathrm{mg} / \mathrm{kg}$ : $41.5 \%, P=0.002$; belimumab $10 \mathrm{mg} / \mathrm{kg}: 51.5 \%, P<0.0001)$. This response maintained a statistically significant value even at week 76 only in the $10 \mathrm{mg} / \mathrm{kg}$ arm.

The combined analysis was performed collecting data from 1,684 patients enrolled in the two phase III studies. This analysis confirmed the results of the BLISS-52 and BLISS76 trials and showed that belimumab allowed a significantly greater number of patients to reduce the prednisone dosage below $7.5 \mathrm{mg} / \mathrm{die}$ (18\% in the $10 \mathrm{mg} / \mathrm{kg}$ group compared to $12 \%$ in controls, $P<0.05)$. Also, the average number of flares/year per patient was significantly lower in the $10 \mathrm{mg} / \mathrm{kg}$ belimumab group compared to controls (2.9 versus 3.5, $P<0.001$ ), but no significant differences were observed in the number of severe flares/year ( 0.8 in the $10 \mathrm{mg} / \mathrm{kg}$ group compared to 1.0 in controls).

The safety profile of both doses of belimumab $(1 \mathrm{mg} / \mathrm{kg}$ and $10 \mathrm{mg} / \mathrm{kg}$ ) indicated that they were generally well tolerated. There were no significant differences between belimumab and placebo in terms of overall and serious dosedependent adverse events. No differences were observed in events leading to discontinuation of treatment. The majority of adverse events were mild or moderate. Table 3 shows the most common adverse events observed in phase II and III trials [41-43].

3.3. Cost-Effectiveness Analysis. The cost-effectiveness analysis showed that belimumab was cost-effective at the base case. In particular, from the Italian NHS perspective, ICER was equal to $€ 22,990$ and $€ 32,859$, respectively, for LY and QALY gained (Table 4 ). The results from the societal perspective 
TABLE 2: Main characteristics and results of the randomized controlled trials on belimumab.

\begin{tabular}{|c|c|c|c|}
\hline Study name (phase) & Study design & Study population & Main results \\
\hline $\begin{array}{l}\text { LBSL02 (Phase II) } \\
\text { [41] }\end{array}$ & $\begin{array}{l}\text { Randomized, double } \\
\text { blinded, controlled } \\
\text { (belimumab } 10 \mathrm{mg} / \mathrm{kg}+ \\
\text { SoC versus belimumab } \\
4 \mathrm{mg} / \mathrm{kg}+\mathrm{SoC} \text { versus } \\
\text { belimumab } 1 \mathrm{mg} / \mathrm{kg}+\mathrm{SoC} \\
\text { versus placebo }+ \text { SoC) }\end{array}$ & $\begin{array}{l}449 \text { adult subjects } \\
\text { with positive } \\
\text { antibodies or positive } \\
\text { antibodies history } \\
\text { and SELENA SLEDAI } \\
\text { flare index } \geq 4 \text { from } \\
\text { Canada and US }\end{array}$ & $\begin{array}{l}\text { No significant differences in improvement of } \\
\text { the SELENA SLEDAI flare index by week } 24 \\
\text { and no significant differences in the occurrence } \\
\text { of flares by week } 52 \text {. Evidence of a greater } \\
\text { benefit from belimumab in patients currently } \\
\text { positive for autoantibodies }\end{array}$ \\
\hline $\begin{array}{l}\text { C1056/BLISS-76 } \\
\text { (Phase III) [42] }\end{array}$ & $\begin{array}{l}\text { Randomized, double } \\
\text { blinded, controlled } \\
\text { (belimumab } 10 \mathrm{mg} / \mathrm{kg}+ \\
\text { SoC versus belimumab } \\
1 \mathrm{mg} / \mathrm{kg}+\text { SoC versus } \\
\text { placebo }+ \text { SoC) }\end{array}$ & $\begin{array}{l}819 \text { adult subjects } \\
\text { with positive } \\
\text { antibodies and } \\
\text { SELENA SLEDAI } \\
\text { flare index } \geq 6 \text { from } \\
19 \text { countries (Europe } \\
\text { and North America) }\end{array}$ & $\begin{array}{l}\text { Response at week } 52: 43 \% \text { in the } 10 \mathrm{mg} / \mathrm{kg} \\
\text { belimumab group versus } 34 \% \text { in placebo } \\
\text { group, } P=0.021 . \text { Belimumab reduced the } \\
\text { number of severe flares }(21 \% \text { in the } 10 \mathrm{mg} / \mathrm{kg} \\
\text { belimumab group compared to } 27 \% \text { in placebo } \\
\text { group, } P>0.05)\end{array}$ \\
\hline $\begin{array}{l}\text { C1057 BLISS-52 } \\
\text { (Phase III) [43] }\end{array}$ & $\begin{array}{l}\text { Randomized, double } \\
\text { blinded, controlled } \\
\text { (belimumab } 10 \mathrm{mg} / \mathrm{kg}+ \\
\text { SoC versus belimumab } \\
1 \mathrm{mg} / \mathrm{kg}+\text { SoC versus } \\
\text { placebo }+ \text { SoC) }\end{array}$ & $\begin{array}{l}865 \text { adult subjects } \\
\text { with positive } \\
\text { antibodies and } \\
\text { SELENA SLEDAI } \\
\text { flare index } \geq 6 \text { from } \\
13 \text { countries (East } \\
\text { Europe, Asia, and } \\
\text { South America) }\end{array}$ & $\begin{array}{l}\text { Response at week } 52: 58 \% \text { in the } 10 \mathrm{mg} / \mathrm{kg} \\
\text { belimumab group versus } 44 \% \text { in placebo } \\
\text { group, } P<0.001 \text {. Belimumab significantly } \\
\text { reduced the number of severe flares ( } 14 \% \text { in the } \\
10 \mathrm{mg} / \mathrm{kg} \text { group compared to } 23 \% \text { in placebo } \\
\text { group, } P=0.006 \text { ). Belimumab allowed a } \\
\text { greater number of patients to reduce the } \\
\text { prednisone dosage below } 7.5 \mathrm{mg} / \text { die ( } 19 \% \text { in the } \\
10 \mathrm{mg} / \mathrm{kg} \text { group compared to } 12 \% \text { in placebo } \\
\text { group, } P=0.053 \text { ) }\end{array}$ \\
\hline
\end{tabular}

TABLE 3: Adverse effects more commonly reported in LBSL02, C1056, and C1057 studies-combined analysis [12].

\begin{tabular}{lccc}
\hline Symptom & Placebo & Belimumab 1 mg/kg & Belimumab 10 mg/kg \\
& $N=675$ & $N=673$ & $138(20.5 \%)$ \\
\hline Headache & $140(20.7 \%)$ & $128(19.0 \%)$ & $142(21.1 \%)$ \\
Upper airways infection & $130(19.3 \%)$ & $100(14.9 \%)$ & $118(17.5 \%)$ \\
Arthralgia & $112(16.6 \%)$ & $88(13.1 \%)$ & $109(16.2 \%)$ \\
Nausea & $82(12.1 \%)$ & $92(13.7 \%)$ & $99(14.7 \%)$ \\
Urinary tract infection & $82(12.1 \%)$ & $81(12.0 \%)$ & $87(12.9 \%)$ \\
Diarrhea & $62(9.2 \%)$ & $71(10.5 \%)$ & $80(11.9 \%)$ \\
Asthenia & $70(10.4 \%)$ & $52(7.7 \%)$ & $66(9.8 \%)$ \\
Pyrexia & $52(7.7 \%)$ & $65(9.6 \%)$ & \\
\hline
\end{tabular}

TABLE 4: Base case results (NHS perspective).

\begin{tabular}{lccc}
\hline & SoC & Belimumab & Difference \\
\hline Life years & 18.99 & 19.76 & 0.77 \\
QALYs & 10.78 & 11.31 & 0.538 \\
Costs & $€ 125,234$ & $€ 142,921$ & $€ 17,688$ \\
ICUR & & & $€ 32,859$ \\
ICER & & & $€ 22,990$ \\
\hline
\end{tabular}

SoC: standard of care; QALY: quality adjusted life year; ICUR: incremental cost-utility ratio; ICER: incremental cost-effectiveness ratio.

confirmed that belimumab can be considered even more costeffective achieving $€ 20,119$ for LY gained and $€ 28,754$ for QALY gained.

The base case results were confirmed by the PSA. The PSA showed that when the threshold/QALY was equal to
$€ 30,000$, belimumab was $29.1 \%$ more likely to be costeffective compared to the SoC. The CEAC showed that, when the willingness to pay/QALY was equal to $€ 40,000$, belimumab was $84.3 \%$ more likely to be cost-effective (Figure 2). The univariate sensitivity analysis showed that main drivers of cost-effectiveness were the treatment effect and the discontinuation rate.

In conclusion, on the basis of CEAC, it is possible to state that the introduction of belimumab within the Italian context could be recommended as it is cost-effective from both NHS and societal perspectives.

3.4. Organizational Aspects and Impacts. The functional status of the patients with SLE, especially during the phase of active disease, is generally compromised when compared with that of the general population. Patients also show a decrease in QoL in the sphere of both physical and emotional 


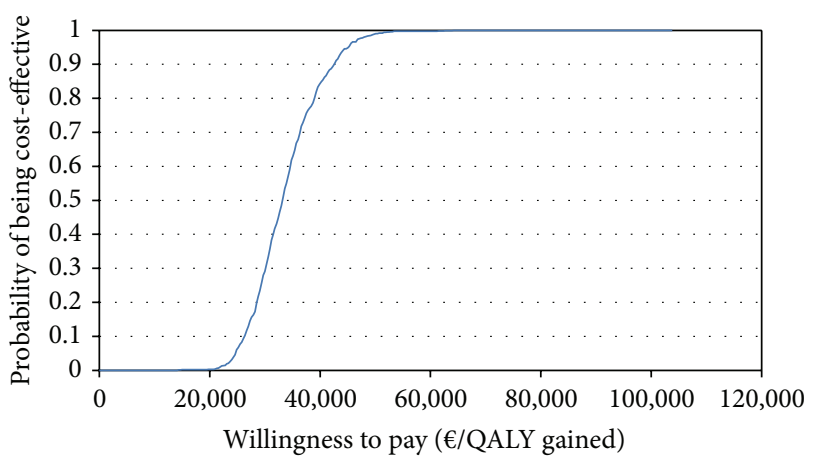

Figure 2: Probability of cost-effectiveness of belimumab according to the cost-effectiveness acceptability curve.

functions. The reduction of Health-Related Quality of Life (HR-QoL) is comparable to that of serious diseases such as acquired immunodeficiency syndrome (AIDS) or other chronic diseases such as rheumatoid arthritis, hypertension, congestive heart failure, diabetes mellitus, and myocardial infarction $[44,45]$.

The available studies concerning the impact of belimumab on QoL showed a significant improvement in QoL in comparison to the control group (SoC), confirming the positive effect of the drug on the different dimensions of HRQoL $[46,47]$.

The diagnosis of SLE is often late, largely due to the insidious onset of the disease [24]. Patients frequently need the advice and active cooperation of several specialists (rheumatologists, internists, nephrologists, immunologists, and dermatologists) and are hampered by the low prevalence of the disease [36], the late diagnosis [24], the strong interand intraregional heterogeneity in accessing new therapiesespecially in the case of infusion therapies-and the lack of specific clinical pathways.

According to the results of a survey carried out in Italy in 2011, SLE is treated in one out of four hospitals, and only $55 \%$ of centers treating SLE provide patients with intravenous biological drugs commonly used in the treatment of other diseases [48]. The complexity of taking charge of the patient and the use of off-label drugs represent further issues to be considered. In this context, belimumab would help to bridge the therapeutic gap for SLE, by adding value in terms of offering appropriate treatments and improvement of QoL.

3.5. Ethical Evaluation. On the basis of phase III clinical trials, belimumab has a favorable risk-benefit profile even though further studies are needed to address the safety profile outside clinical research studies. Available studies also showed that belimumab can improve QoL. An adequate communication process about the possible risks and benefits, way of administering, and follow-up schedule, is required to guarantee the autonomy of the patient. The involvement of general practitioners (GPs), if integrated with specialist centers, might be an appropriate solution for diagnosis and timely initiation of therapy and to facilitate the communication process. The only critical point seems to be social justice, which is threatened by economic constraints and heterogeneity in access to care within Italy.

To guarantee the correct use of belimumab, several actions are needed: the promotion of integration between primary care and specialists, in order to allow a multidisciplinary approach to the management of this clinical condition; the collection of further evidence about efficacy, cost-effectiveness, and safety; and the guarantee of an equal access to clinical pathways and drugs for all the patients.

Notwithstanding, current evidence justifies a positive ethical evaluation of the use of belimumab.

\section{Discussion}

Belimumab represents the first drug approved in the last 50 years specifically to treat patients with active, autoantibody positive SLE who are receiving standard therapy. Prior to belimumab, the last drugs approved by the FDA were Plaquenil (hydroxychloroquine) and corticosteroids in 1955. This delay of development of new lupus drugs could be attributed in conducting phase III studies for regulatory approval. In fact, these studies have an intrinsic complexity related to the particular characteristics of such a complex disease as SLE and to the uneasy definition of the endpoints used to evaluate the efficacy of drugs.

The results of the HTA report presented in this paper show the advantages of belimumab by demonstrating its efficacy, cost-effectiveness, and ethical value which make it a useful therapeutic option with the potential to modify the course of SLE. With respect to efficacy, the HTA report by NICE [49] highlighted that there is an evidence of the clinical effectiveness of belimumab, although a greater consistency of results was observed in BLISS-52 trial, which is not as representative as BLISS-76 of European population. NICE assessment concluded that belimumab was not costeffective in comparison to SoC but judged appropriately the projection of data about outcomes from short to long term. Notwithstanding, NICE appraisal highlighted different concerns related to the model and its parameters, which may lead to either an over- or an underestimation of the ICER. In particular, since the discontinuation rate could have been underestimated, the ICER has been overestimated. This is relevant also because the discontinuation rate is likely to be higher as shown from the phase II extension study and agreed by clinicians [49].

Finally, the NICE HTA report considered the characteristics of the population affected by the disease and the lack of other licensed treatments. Furthermore, belimumab was considered steroid sparing with the potential to reduce the side effects of these drugs.

Our report thoroughly dealt with epidemiological, economic, organizational, and ethical implications of the use of belimumab in the Italian context, making it possible to support a final positive opinion about the drug.

In fact SLE is a highly health-threatening disease which mainly affects not only women of childbearing age, but also adult males, children, and adolescents. The disease is also burdened with high social and health services costs. Chronic treatment with standard care exposes patients to health risks 
TABLE 5: Main parameters used in the base case scenario.

\begin{tabular}{lc}
\hline Age (years)—mean & 34.7 \\
\hline Gender (\% female) & $93.9 \%$ \\
\hline $\begin{array}{l}\text { Length of disease (years) - mean } \\
\text { Age at the moment of the diagnosis } \\
\text { (years) — mean }\end{array}$ & 6.6 \\
\hline$\%$ Afro-Caribbean & 28.1 \\
\hline $\begin{array}{l}\text { SLICC (Systemic Lupus International } \\
\text { Collaborating Clinics Damage_mean Index) }\end{array}$ & 0.61 \\
\hline SLEDAI-mean & 10.9 \\
\hline Daily steroid dose (mg/day)—mean & 11.6
\end{tabular}

The characteristics are determined by pooling the patient-level data from BLISS-52 and BLISS-76 for placebo and belimumab $10 \mathrm{mg} / \mathrm{kg}$.

and patients with high disease activity need alternatives to drug holidays or the increase in the dosage of other drugs. In some cases clinicians use therapies which are not indicated for SLE (off-label drugs), such as rituximab.

Our literature review showed that the prevalence of SLE is about 47 per 100,000 for a total of 28,500 patients in Italy. About $50 \%$ of patients are affected by the active form despite SoC. These patients, if positive to anti-dsDNA and with low complement, are eligible to receive belimumab. Furthermore SLE determines an increase in mortality and work disability with costs varying according to disease severity and the development of flares. According to efficacy data, belimumab in association with SoC would prevent 4,742 flares in three years and would be cost-effective. The definition of a clear and efficient treatment pathway for SLE would be worthwhile and requires the involvement of GPs as well as several specialists. Furthermore, belimumab could improve the QoL with positive ethical implications.

In conclusion, no other treatment obtained similar significant or comparable results. However there is a lack in long term efficacy data and also the evidence of the correlation between the SRI and survival should be strengthened. Furthermore safety profile was studied only for a maximum period of seven years of follow-up, which is still inadequate given the chronic nature of the disease. Efficacy data only come from studies versus placebo, since no other treatment proved a significant effect on the control of the disease.

Despite these limits, the strength of this work was the collection, combination, and synthesis of all available data which are important in order to support the sustainable introduction of a new drug. In this view, belimumab may be an innovative and important drug, and postmarketing research will play a key role in updating the HTA and further supporting decision making.

In conclusion this project demonstrates that belimumab may deserve to be introduced in the care of SLE patients in Italy. Our work suggests that tools such as HTA, characterized by a comprehensive approach to the evaluation of health technologies, should be used and implemented in the view of supporting an informed and evidence based decision making process [50].

\section{Conclusion}

The HTA described in this paper shows the value of belimumab and gives important information for its proper use. In particular, the assessment demonstrated that belimumab may prevent flares and is cost-effective in patients with systemic lupus erythematosus who have a highly active disease despite standard of care.

\section{Appendix}

\section{Main Parameters Used in the Base Case Scenario}

See Table 5.

\section{Conflict of Interests}

The authors declare that there is no conflict of interests regarding to the publication of this paper.

\section{Acknowledgments}

The work was supported by GlaxoSmithKline which sponsored the study design, the collection, analysis, and interpretation of data. The authors declare that they received consulting fee from the Company in order to carry out the project.

\section{References}

[1] N. F. Rothfield, "Systemic lupus erythematosus: clinical aspects and treatment," in Arthritis and Allied Conditions: A Textbook of Rheumatology, E. J. McCarthy, Ed., Lea \& Febiger, Philadelphia, $\mathrm{Pa}$, USA, 11th edition, 1989.

[2] D. D. Gladman, M. B. Urowitz, P. Rahman, D. Ibañez, and L. Tam, "Accrual of organ damage over time in patients with systemic lupus erythematosus," Journal of Rheumatology, vol. 30, no. 9, pp. 1955-1959, 2003.

[3] T. Stoll, N. Sutcliffe, J. Mach, R. Klaghofer, and D. A. Isenberg, "Analysis of the relationship between disease activity and damage in patients with systemic lupus erythematosus-a 5-yr prospective study," Rheumatology, vol. 43, no. 8, pp. 1039-1044, 2004.

[4] M. Mosca, D. Boumpas, I. N. Bruce et al., "Treat-to-target in systemic lupus erythematosus: where are we today?" Clinical and Experimental Rheumatology, vol. 30, no. 4, pp. S112-S115, 2012.

[5] G. Bertsias, J. P. A. Ioannidis, J. Boletis et al., "EULAR recommendations for the management of systemic lupus erythematosus. Report of a Task Force of the EULAR Standing Committee for International Clinical Studies Including Therapeutics," Annals of the Rheumatic Diseases, vol. 67, no. 2, pp. 195-205, 2008.

[6] G. K. Bertsias, J. P. A. Ioannidis, M. Aringer et al., "EULAR recommendations for the management of systemic lupus erythematosus with neuropsychiatric manifestations: report of a task force of the EULAR standing committee for clinical affairs," Annals of the Rheumatic Diseases, vol. 69, no. 12, pp. 2074-2082, 2010. 
[7] B. H. Hahn, M. A. McMahon, A. Wilkinson et al., "American College of Rheumatology guidelines for screening, treatment, and management of lupus nephritis," Arthritis Care and Research, vol. 64, no. 6, pp. 797-808, 2012.

[8] A. Doria and L. Iaccarino, “Terapia del LES. In: L'impiego di belimumab nel Lupus Eritematoso Sistemico: risultati di una valutazione di HTA," QIJPH, vol. 2, no. 1, pp. 37-53, 2013.

[9] M. Nikpour, M. B. Urowitz, D. Ibañez, and D. D. Gladman, "Frequency and determinants of flare and persistently active disease in systemic lupus erythematosus," Arthritis Care and Research, vol. 61, no. 9, pp. 1152-1158, 2009.

[10] M. Zen, N. Bassi, L. Nalotto et al., "Disease activity patterns in a monocentric cohort of SLE patients: a seven-year follow-up study," Clinical and Experimental Rheumatology, vol. 30, no. 6, pp. 856-863, 2012.

[11] European Medicines Agency, "Benlysta," 2014, http://www ema.europa.eu/ema/index.jsp?curl=pages/medicines/human/ medicines/002015/human_med_001466.jsp\&murl=menus/medicines/medicines.jsp\&mid=WC0b01ac058001d125.

[12] M. A. Petri, R. A. Levy, J. T. Merrill et al., "Belimumab, a BLyS-specific inhibitor, reduced disease activity, flares, and prednisone use in patients with seropositive SLE: combined efficacy results from the phase 3 BLISS-52 and -76 studies," Arthritis \& Rheumatism, vol. 62, supplement 10, abstract 452, 2010.

[13] M. Petri, "Lupus in Baltimore: evidence-based "clinical pearls" from the Hopkins Lupus Cohort," Lupus, vol. 14, no. 12, pp. 970973, 2005.

[14] Evidence Review Group Report commissioned by the National Health Service Research and Development Programme on behalf of the National Institute for Health and Clinical Evidence, "Belimumab for the treatment of active autoantibodypositive systemic lupus erythematosus," http://www.hta.ac.uk/ project/2527.asp.

[15] Italian Ministry of Health. Italian National Tariffs, 2013, http://www.salute.gov.it/portale/temi/p2_6.jsp?lingua=italiano \&id=1767\&area=programmazioneSanitariaLea\&menu=lea.

[16] G. Fattore and A. Torbica, "Cost and reimbursement of cataract surgery in Europe: a cross-country comparison," Health Economics, vol. 17, no. 1, pp. S71-S82, 2008.

[17] M. Pugliatti, P. Sobocki, E. Beghi et al., "Cost of disorders of the brain in Italy," Neurological Sciences, vol. 29, no. 2, pp. 99-107, 2008.

[18] P. Piscitelli, G. Iolascon, M. Greco et al., "The occurrence of acute myocardial infarction in Italy: a five-year analysis of hospital discharge records," Aging-Clinical and Experimental Research, vol. 23, no. 1, pp. 49-54, 2011.

[19] A. Della Rossa, R. Neri, R. Talarico et al., "Diagnosis and referral of rheumatoid arthritis by primary care physician: results of a pilot study on the city of Pisa, Italy," Clinical Rheumatology, vol. 29, no. 1, pp. 71-81, 2010.

[20] G. Turchetti, L. Scalone, O. Della Casa Alberighi et al., "The rationale of pharmacoeconomic analysis in rheumatologic indications," Clinical and Experimental Rheumatology, vol. 30, no. 4, pp. S64-S71, 2012.

[21] G. Turchetti, J. Yazdany, and I. Palla, "SLE and the economic perspective: a systematic literature review and points to consider," Clinical and Experimental Rheumatology, vol. 30, no. 4, supplement 73, pp. S116-S122, 2012.

[22] M. Petri, "Review of classification criteria for systemic lupus erythematosus," Rheumatic Disease Clinics of North America, vol. 31, no. 2, pp. 245-254, 2005.
[23] M. Petri, A. M. Orbai, G. S. Alarcón et al., "Derivation and validation of the systemic lupus international collaborating clinics classification criteria for systemic lupus erythematosus," Arthritis \& Rheumatology, vol. 64, no. 8, pp. 2677-2686, 2012.

[24] A. M. Bertoli, L. M. Vilá, J. D. Reveille, and G. S. Alarcón, "Systemic lupus erythaematosus in a multiethnic US cohort (LUMINA) LIII: disease expression and outcome in acute onset lupus," Annals of the Rheumatic Diseases, vol. 67, no. 4, pp. 500504, 2008.

[25] N. Ruperto, L. M. Hanrahan, G. S. Alarcón et al., "International consensus for a definition of disease flare in lupus," Lupus, vol. 20, no. 5, pp. 453-462, 2011.

[26] A. J. G. Swaak, H. G. van Den Brink, R. J. T. Smeenk et al., "Systemic lupus erythematosus: clinical features in patients with a disease duration of over 10 years, first evaluation," Rheumatology, vol. 38, no. 10, pp. 953-958, 1999.

[27] M. R. Ehrenstein and D. A. Isenberg, "Systemic lupus erythematosus in adults-clinical features and aetiopathogenesis," in Oxford Textbook of Rheumatology, D. A. Isenberg, P. J. Maddison, P. Woo et al., Eds., Oxford University Press, Oxford, UK, 2004.

[28] P. Maddison, V. Farewell, D. Isenberg et al., "The rate and pattern of organ damage in late onset systemic lupus erythematosus," Journal of Rheumatology, vol. 29, no. 5, pp. 913-917, 2002.

[29] M. Faurschou, H. Starklint, P. Halberg, and S. Jacobsen, "Prognostic factors in lupus nephritis: diagnostic and therapeutic delay increases the risk of terminal renal failure," Journal of Rheumatology, vol. 33, no. 8, pp. 1563-1569, 2006.

[30] S. M. Korbet, E. J. Lewis, M. M. Schwartz, M. Reichlin, J. Evans, and R. D. Rohde, "Factors predictive of outcome in severe lupus nephritis," The American Journal of Kidney Diseases, vol. 35, no. 5, pp. 904-914, 2000.

[31] M. Petri, "Epidemiology of systemic lupus erytematosus," Best Practice \& Research Clinical Rheumatology, vol. 16, no. 5, pp. 847-858, 2002.

[32] V. Rus, E. E. Maury, and M. C. Hochberg, "The epidemiology of systemic lupus erythematosus," in Dubois'Lupus Erythematosus, D. J. Wallace and B. H. Hahn, Eds., Lippincott Williams \& Wilkins, Philadelphia, Pa, USA, 2002.

[33] M. Govoni, G. Castellino, S. Bosi, N. Napoli, and F. Trotta, "Incidence and prevalence of systemic lupus erythematosus in a district of North Italy," Lupus, vol. 15, no. 2, pp. 110-113, 2006.

[34] M. Benucci, A. Del Rosso, F. Li Gobbi, M. Manfredi, M. M. Cerinic, and C. Salvarani, "Systemic lupus erythematosus (SLE) in Italy: an Italian prevalence study based on a two-step strategy in an area of Florence (Scandicci-Le Signe)," Medical Science Monitor, vol. 11, no. 9, pp. CR420-CR425, 2005.

[35] A. Doria, Z. Amoura, R. Cervera et al., "Annual direct medical cost of active systemic lupus erythematosus in five European countries," Annals of the Rheumatic Diseases, vol. 73, pp. 154160, 2014.

[36] J. E. Davidson, N. Galway, and P. J. Egger, "The prevalence of systemic lupus erythematosus in Europe: a systematic review and meta-analysis," in Proceedings of the European League Against Rheumatism (EULAR '12), Berlin, Germany.

[37] S. Bernatsky, J.-F. Boivin, L. Joseph et al., "Mortality in systemic lupus erythematosus," Arthritis and Rheumatism, vol. 54, no. 8, pp. 2550-2557, 2006.

[38] A. Doria, L. Iaccarino, A. Ghirardello et al., "Long-term prognosis and causes of death in systemic lupus erythematosus," The American Journal of Medicine, vol. 119, no. 8, pp. 700-706, 2006. 
[39] P. Katz, A. Morris, L. Trupin, J. Yazdany, and E. Yelin, "Disability in valued life activities among individuals with systemic lupus erythematosus," Arthritis Care and Research, vol. 59, no. 4, pp. 465-473, 2008.

[40] Human Genome Sciences, "Arthritis Advisory Committee Meeting Briefing Document for the 16 November 2010 Meeting," 2010, http://www.fda.gov/downloads/AdvisoryCommittees/CommitteesMeetingMaterials/Drugs/ArthritisDrugsAdvisoryCommittee/UCM23358.

[41] D. J. Wallace, W. Stohl, R. A. Furie et al., "A phase II, randomized, double-blind, placebo-controlled, dose-ranging study of belimumab in patients with active systemic lupus erythematosus," Arthritis Care and Research, vol. 61, no. 9, pp. 1168-1178, 2009.

[42] R. Furie, M. Petri, O. Zamani et al., " A phase III, randomized, placebo-controlled study of belimumab , a monoclonal antibody that inhibits B lymphocyte stimulator, in patients with systemic lupus erythematosus," Arthritis \& Rheumatology, vol. 63, 3918, no. 12, p. 3930, 2011.

[43] S. V. Navarra, R. M. Guzmán, A. E. Gallacher et al., "Efficacy and safety of belimumab in patients with active systemic lupus erythematosus: a randomised, placebo-controlled, phase 3 trial," The Lancet, vol. 377, no. 9767, pp. 721-731, 2011.

[44] J. Thumboo and V. Strand, "Health-related quality of life in patients with systemic lupus erythematosus: an update," Annals of the Academy of Medicine Singapore, vol. 36, no. 2, pp. 115-122, 2007.

[45] C.-S. Yee, K. McElhone, L.-S. Teh, and C. Gordon, "Assessment of disease activity and quality of life in systemic lupus erythematosus—new aspects," Best Practice \& Research Clinical Rheumatology, vol. 23, no. 4, pp. 457-467, 2009.

[46] V. Strand, B. Crawford, M. Petri et al., "LBSL02 Study Group. Responders defined by SELENA SLEDAI, BILAG and physicians global assessment of disease activity report stabilization and/or improvement in health-related quality of life (HRQOL) following treatment with belimumab," in Proceedings of the Annual European Congress of Rheumatology (EULAR '07), Barcelona, Spain, 2007.

[47] Y. M. Kang, K. W. Lee, E. B. Ramiterre et al., "Belimumab, a BLySspecific inhibitor, significantly improved physical functioning, fatigue, and other health-related quality of life (HRQoL) measures in patients with seropositive," International Journal of the Rheumatic Diseases, vol. 13, supplement 1, pp. 110115, 2010.

[48] Cegedim Strategic Data, "Survey Lupus Eritematosus Sistemico. Interviste telefoniche con metodologia CATI (integrate da interviste F2F sugli ospedali piu importanti) su 936 Ospedali," Periodo di rilevazione maggio-giugno 2011.

[49] National Institute for Health and Clinical Excellence. Belimumab for the treatment of active autoantibody-positive systemic lupus erythematosus, 2013, http://guidance.nice.org .uk/index.jsp?action=byID\&o=13307.

[50] W. Ricciardi and G. La Torre, Eds., Health Technology Assessment. Principi, Dimensioni, Strumenti, Seed, Torino, Italy, 2010. 


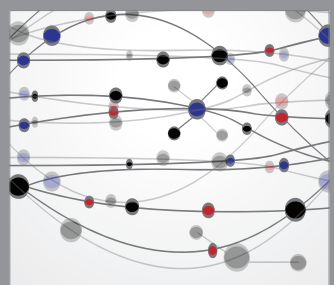

The Scientific World Journal
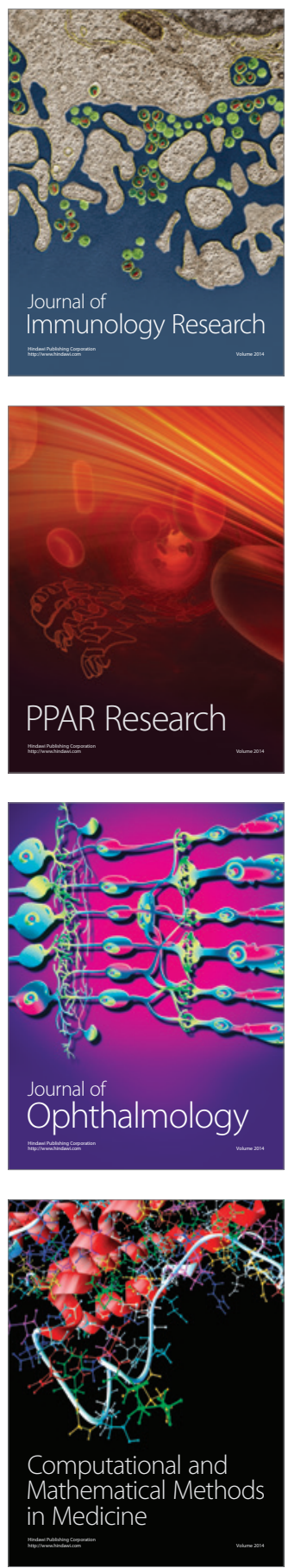

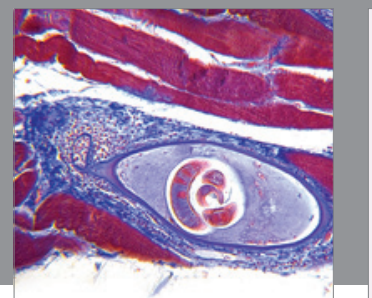

Gastroenterology

Research and Practice
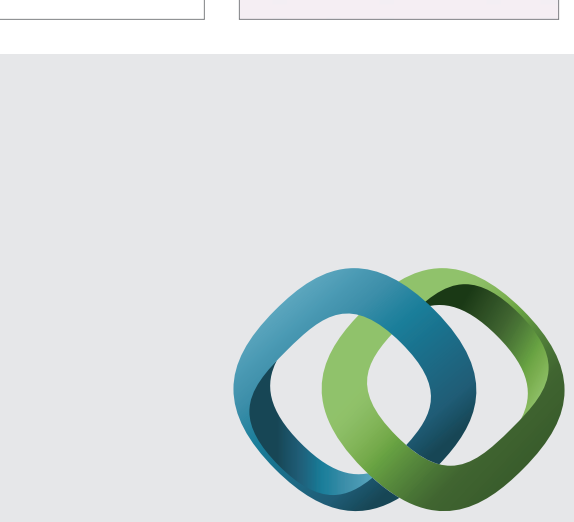

\section{Hindawi}

Submit your manuscripts at

http://www.hindawi.com
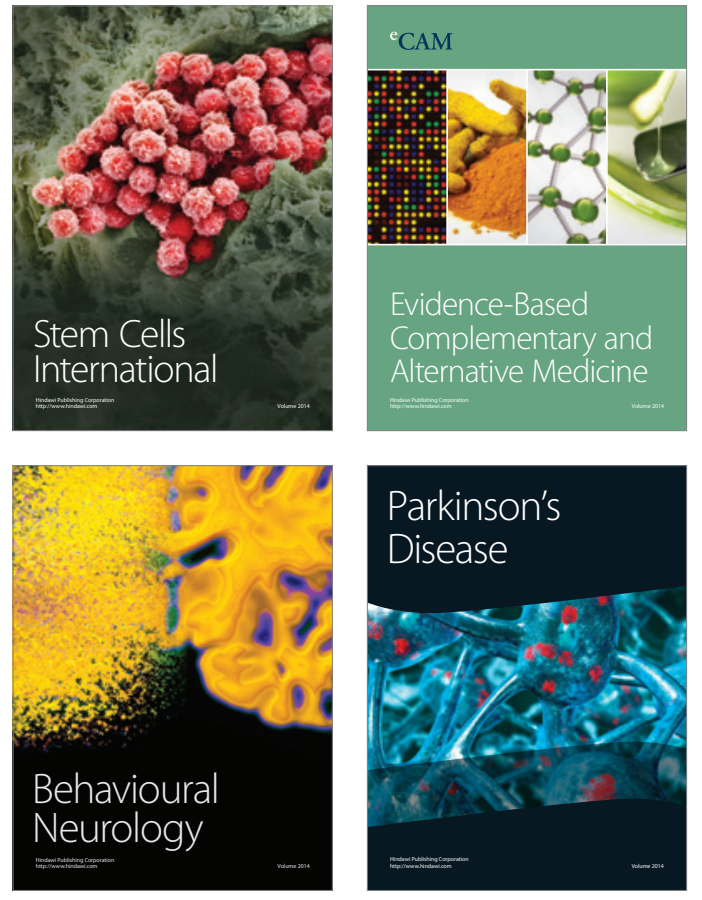
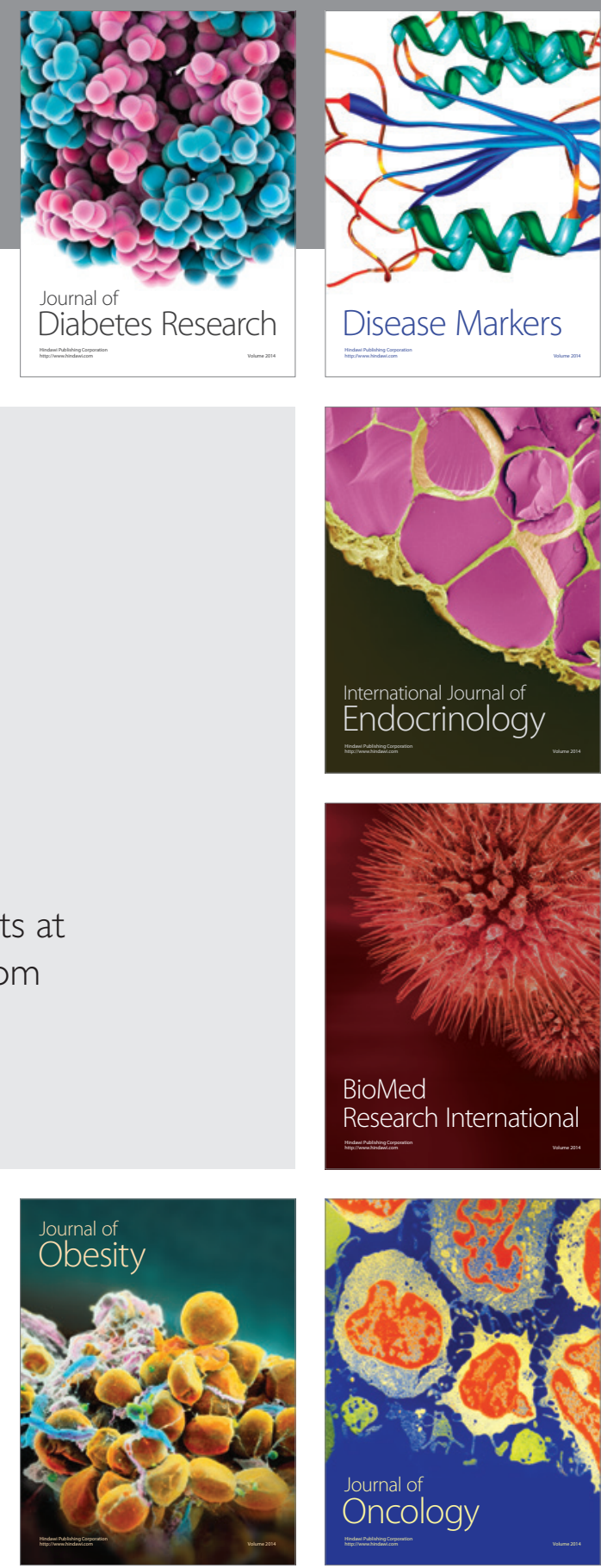

Disease Markers
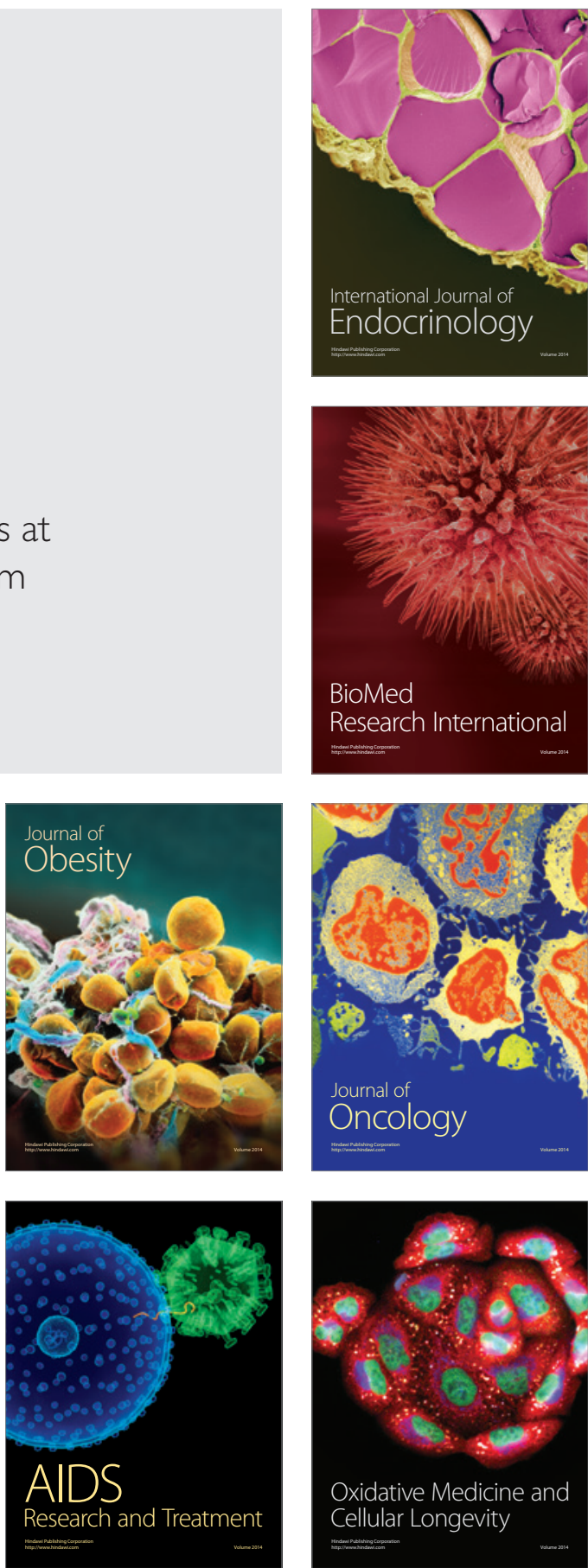